\title{
An Effort to Improve Self-Regulated Learning of Secondary Middle School Students Through Autograph-Assisted Mathematics Realistic Approach
}

\author{
Roima Rizki Lestari ${ }^{1}$ \\ ${ }^{1}$ College Student, Mathematics Education Program \\ Universityof Medan \\ Medan, Indonesia \\ Email: roimarizki93@gmail.com
}

\author{
Mulyono $^{2}$ \\ ${ }^{3}$ Lecturer, Mathematics Education Program \\ Universityof Medan \\ Medan, Indonesia
}

\begin{abstract}
This study aims to investigate (1) the improvement of students' self-regulated learning (SRL) through Autographassisted realistic mathematics education approach (ARME), (2) The existence of the interaction between the learning approach and the initial mathematical ability (IMA) of the improvement of students SRL, (3) the process of self-regulated learning. The instrument used consisted of the SRL test. Data were analyzed through two-way ANOVA. Before using ANOVA, homogeneity and normality are first tested. Based on the results of the analysis, the findings of the study are: (1) the improvement in SRL of students in ARME class is higher than the improvement in SRL of students in conventional class, (2) there is no interaction between learning approach with IMA in improving SRL, (3) The process of self-regulated learning that made by the students in ARME class is better than students in conventional class, that means students in the ARME class show more systematic and directed self-regulated learning steps. Research findings recommend that the ARME approach be one of the learning approaches used in schools, especially to improve SRL.
\end{abstract}

Keywords: self-regulated learning, realistic mathematics education approach, autograph-software.

\section{INTRODUCTION}

Education is a place where humans are fostered, grown, and developed their potentials. The virtue in education is the learning process. According to Nesusin, et.al. : "The learning process must provide several benefits for students so that they can develop their abilities fully" [1]. The more potential a person is developed, the more able he is to face changes in the conditions in life that are always developing in the present and in the future that occur globally. Learning that can benefit a lot is learning mathematics. According to Freudenthal, "learning mathematics is doing mathematics by self-regulated learning as dynamic and interactive activities such as finding, exploring, looking for relationships and proving it" [2]. Shimizu (in Isoda, 2010) explains that the teaching approach which includes innovative learning is teaching mathematics which starts from the problems of children in the real world [3].
In building their knowledge, students must be directly involved in concrete experiences before learning abstract mathematical concepts, then invited to focus on finding mathematical concepts and connect them to existing knowledge so that students will feel involved in the discovery of mathematical concepts. In line with this statement, teaching mathematics should give high-level thinking skills (high order thinking skills, abbreviated HOTS) which includes the ability of understanding, reasoning, connection and representation, and problem solving abilities [4]. In fact, in evaluation report by TIMSS (Trend in International Mathematics and Science Studies) year 2003, 2007, and 2012 [5], Some other research results show the weaknesses of students SRL([6], [7], [8]). In addition, the ability to learn mathematics, the learning independence of junior high school students is also still low [9],. The so-called great level is defined as the attitude that is driven by the desire, initiative, and responsibility to learn and find out and learn from others. Also found experts Schunk and Zimmerman its use "as a learning process that occurs because of the influence of thoughts, strategies, and strategies that influence the achievement of goals [10], In the taxonomy of learning objectives, learning independence is included in the affective domain [11],. So far the school has focused more attention on the cognitive domain of students, rarely schools that seriously work on the affective side. Lack of aspects of independence can benefit significantly in the course of one's life. Lack of independence in learning forms an attitude characterized by individual tendencies (counter-collaborative), unable to distinguish others, intolerant, arrogant, and so on Education experts are an effective solution for learning and learning from the factors that have been carried out in conventional schools.

Educational experts suspect that SRL students are in the low category due to learning factors that have been run in conventional schools ([12], [13], [14], [15]), even though the SRL can be developed in schools; one way to develop it is through Realistic Mathematic Education (RME). Gravemeijer stated that RME is a learning approach that starts every beginning of learning by proposing real-life problems (called problem scenarios) to students in small groups (collaborative) 
[16]. Experts believe that RME can improve self-regulated learning abilities ([17], [18], [19]).

During the process of RME approach, students will be more easily involved in self-regulated learning if learning is combined with the use of computer and communication technology (ICT). The use of ICT is one of the six principles of learning mathematics; technology is essential in teaching and learning mathematics; it influences the mathematics that is taught and improves students' learning"; or application in class, the use of ICT can be integrated to several learning approach [20]. Karnasih states that there are four different approaches that can be implemented in integrating ICT to teaching and learning mathematics: 1) Expository learning; 2) Inquiry based learning; 3) Cooperative learning; and 4) Individual learning [21].

The above statement from Karnasih shows that the use of ICT is suitable if integrated in learning to improve selfregulated learning skills. One software that can help teaching mathematics is autograph. Autograph itself was recommended by Curriculum and Evaluation Standards for School Mathematics [22]. By using autograph, students can explore, investigate and search. By using autograph, students get an aid to solving mathematical problems. Students can retry solving the problem in a short period of time than just using hands, so that from the experiment students can find, construct and deduce mathematical principles, and finally understand mathematical concepts.

Based on the literature study, it can be said that autographassisted realistic mathematics education approach (ARME) can be expected to improve students' self-regulated learning skills.

\section{THEORETICAL FRAMEWORK}

Realistic Mathematics Education (RME) is a teaching and learning theory in mathematics education that was first introduced and developed by the Freudenthal Institute in the Netherlands. This theory has been adopted by a large number of countries all over the world such as England, Germany, Denmark, Spain, Portugal, South Africa, Brazil, USA, Japan, and Malaysia. [23]. The present form of RME is mostly determined by Freudenthal's view on mathematics [24].

Freudenthal has two important points of views, that is, mathematics must be connected to reality and mathematics is as human activity. First, mathematics must be close to children and be relevant to everyday life situations. However, the word realistic', refers not just to the connection with the real-world, but also refers to problem situations which real in students' mind. For the problems to be presented to the students this means that the context can be a real-world but this is not always necessary. De Lange stated that problem situations can also be seen as applications or modeling. Second, the idea of mathematics as a human activity is stressed. Mathematics education organized as a process of guided reinvention, where students can experience a similar process compared to the process by which mathematics was invented. The meaning of invention is steps in learning processes while the meaning of guided is the instructional environment of the learning process. For example, the history of mathematics can be used as a source of inspiration for course design. Moreover, the reinvention principle can also be inspired by informal solution procedures. Informal strategies from the students can often be interpreted as anticipating more formal procedures. In this case, the reinvention process uses concepts of mathematization as a guide.

Two types of mathematization which were formulated explicitly in an educational context by Treffers are horizontal and vertical mathematization.[25]. In horizontal mathematization, the students come up with mathematical tools which can help to organize and solve a problem located in a real-life situation. The following activities are examples of horizontal mathematization: identifying or describing the specific mathematics in a general context, schematizing, formulating and visualizing a problem in different ways, discovering relations, discovering regularities, recognizing isomorphic aspect in different problems, transferring a real world problem to a mathematical problem, and transferring a real world problem to a known mathematical problem. On the other hand, vertical mathematization is the process of reorganization within the mathematical system itself. The following activities are example of vertical mathematization: representing a relation in a formula, proving regularities, refining and adjusting models, using different models, combining and integrating models, formulating a mathematical model, and generalizing.

Freudenthal stated that "horizontal mathematization involves going from the world of life into the world of symbols, while vertical mathematization means moving within the world of symbols."[26].

\section{RESEARCH QUESTIONS}

The research try to improve self-regulated learning ability of the middle secondary school students through autographassisted realistic mathematics education approach (ARME). Research questions are:

1. Is the improvement in SRL of students in the ARME class higher than the improvement in SRL students in conventional classes?

2. Is there an interaction between learning approach and IMA on improving SRL?

3. Is the process of self-regulated learning made by students in the ARME class better than students in conventional class?

\section{RESEARCH METHODS}

In this study, the Autograph-assisted RME approach (ARME) was applied in the experimental class and the conventional approach was used in the control class to convey mathematics material related to statistical problems. The research design used was pretest-posttest control group design. In this design, there are two groups of students where each group is given a pretest to determine the initial mathematical ability (IMA), then posttest to see the final state of selfregulated learning abilities after being treated. 
This research is quasi-experimental because the class used has been formed before. Subject of the study is 36 students of VII SMPN 2 Beringin Deli Serdang. The object of the research was the students' self-regulated learning abilities (SRL) and student activities in the classroom. The instrument used consisted of the SRL test, observation sheet for student activities, and interview guidelines. After finishing SRL test, the activity continued to interview stage. Subjects to be interviewed consisted of students with high, medium and low SRL categories. The interview with the subject was done based on the answer errors written by the students on the SRL test answer sheet. Interviews are open standards that give students the freedom to develop opinions. Interviews are conducted more in depth depending on the situation and condition of the respondent.

\section{RESULT AND DISCUSSION}

The study of students' self-regulated learning abilities (SRL) presented here includes the description, summary of the results of hypothesis testing and analysis of data based on learning, as well as an analysis of the combined effect (interaction) between learning approach and IMA factors (high, medium and low). The learning factors used are Autograph-assisted realistic mathematics education approach (ARME) and conventional approach. At ARME class, the students are learning in small group to self-regulated learning presented in students activity sheet (SAS). While, in control class (conventional class) the students are not grouped, the teacher explained math topic to all students at the classroom.

\section{THE DIFFERENCE OF SELF-REGULATED LEARNING OF THE STUDENTS}

Overall, the data has been tested for normality and homogeneity for both the two-way ANOVA test and the interaction test. The results are significant. Test of average difference in self-regulated learning ability (SRL) was carried out through two-way ANOVA, the results are shown in Table 1.

TABLE 1.ANOVA Result For SRL Data

\begin{tabular}{|l|l|l|l|l|l|}
\hline Source & $\begin{array}{l}\text { Type III } \\
\text { Sum of } \\
\text { Squares }\end{array}$ & Df & $\begin{array}{l}\text { Mean } \\
\text { Square }\end{array}$ & F & Sig. \\
\hline $\begin{array}{l}\text { Corrected } \\
\text { Model }\end{array}$ & $175.947^{\text {a }}$ & 5 & 35.189 & $\begin{array}{l}3.26 \\
0\end{array}$ & .012 \\
\hline Intercept & 12886.613 & 1 & $\begin{array}{l}12886.61 \\
3\end{array}$ & $\begin{array}{l}1193 \\
.985\end{array}$ & .000 \\
\hline $\begin{array}{l}\text { Learning } \\
\text { approach }\end{array}$ & 59.511 & 1 & 59.511 & $\begin{array}{l}5.51 \\
4\end{array}$ & .022 \\
\hline $\begin{array}{l}\text { IMA } \\
\text { Learning } \\
\text { approach*IMA }\end{array}$ & 2.226 & 2 & 1.113 & $\begin{array}{l}.5 .56 \\
3\end{array}$ & .014 \\
\hline Error & 625.990 & 58 & 10.793 & .902 \\
\hline Total & 18292.000 & 64 & & & \\
\hline Corrected Total & 801.938 & 63 & & & \\
\hline
\end{tabular}

a. $\mathrm{R}$ squared $=.219($ Adjusted $\mathrm{R}$ Squared $=.152)$
Based on the test results in Table 1, it can be concluded that the effect of ARME on students' self-regulated learning abilities is better than the influence of conventional learning.

SRL in the ARME class is better than MPSS in conventional class because in the class that implements the ARME approach students solved self-regulated learning regularly and systematically It means, math problems have designed with the objective to improve students SRL. The mathematical problems that students solve in this class are documented in the Student Activity Sheet (SAS). Problems in SAS are designed based aspects, which are understanding problems, planning strategies, implementing strategies, and reflection. In this study, reflection is the activity to interpreted as making a conclusion based on the solution obtained.

In conventional class, students accept math topics that are explained by the teacher, get ways to solve mathematical problems from the teacher's explanation, and practice solving problems according to what the teacher teaches. The mathematical problems that are resolved are still routine problems that do not require problem solving steps. The following is the research design in Table 2.

TABLE 2. Research Design

\begin{tabular}{|c|c|c|c|}
\hline Class & Pretest & Treatment & Posttest \\
\hline Experiment & $\mathrm{O}_{1}$ & $\mathrm{X}$ & $\mathrm{O}_{2}$ \\
\hline Control & $\mathrm{O}_{1}$ & -- & $\mathrm{O}_{2}$ \\
\hline
\end{tabular}

Information :

$\mathrm{O}_{1}=$ Pretest

$\mathrm{O}_{2}=$ Posttest

$\mathrm{X}=$ Autograph-assisted realistic mathematics education approach (ARME)

-- = conventional approach

\section{Interaction Between Learning Approach and IMA to SRL}

Test of interaction between learning factors and IMA factors was carried out using two-way ANOVA. The test results at the alpha level of 0.05 indicate that there is no significant interaction between the learning approach factors and the IMA factors towards the improvement of SRL (see Figure 1). That is, there is no simultaneous effect between the learning approach and the IMA on improving student SRL. SRL improvement is linear 


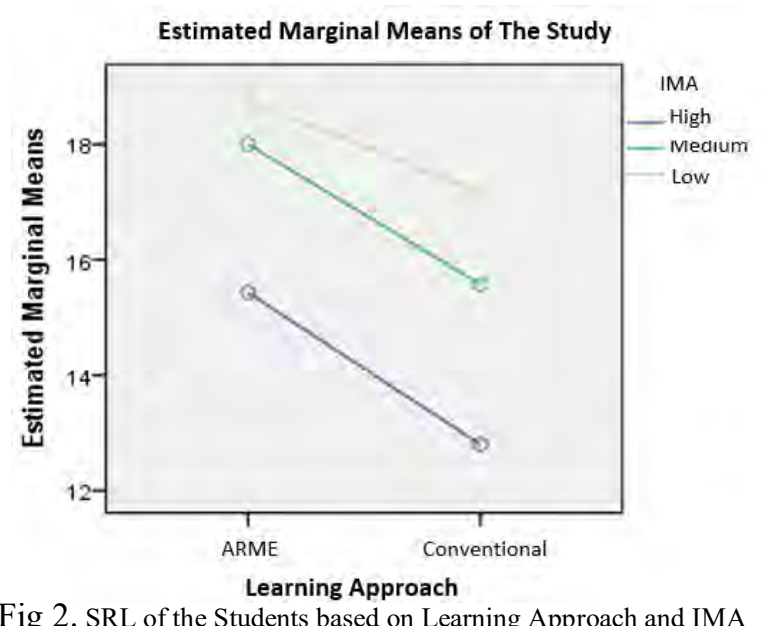

Fig 2. SRL of the Students based on Learning Approach and IMA

\section{CONCLUSION}

Based on some theories, research findings, and research discussions, it can be concluded that:

1. The improvement of self-regulated learning ability of the students taught Autograph-assisted realistic mathematical approach is higher than the improvement in self-regulated learning of the students taught through conventional learning approach.

2. There is no interaction between learning approach and IMA of the student on the improvement of self-regulated learning ability of the students.

3. The process of self-regulated learning of the students at ARME class is better than that process of the students taught through conventional learning approach.

\section{SUGGESTION}

Based on conclusions above, it can be suggested that:

1. Autograph-assister realistic mathematics education approach (ARME) is recommended to be used by mathematics teacher of grade VII in class to improve selfregulated learning ability.

2. In applying ARME, the teacher must manage time carefully in order to keep in mind the activeness of students in learning should fulfill the proportion of ideal time.

3. To other researchers, this research may be used as a reference to obtain quality results when applying ARME to improve self-regulated learning ability and to improve other mathematical thinking skills.

\section{References}

[1] Nesusin, N., Intrarakhamhaeng, P., Supadol, P., Piengkes, N. \& Poonpipathana, S. 2014. Đevelopment of Lesson Plans by the Lesson Study Approach for the 6th Grade Students in Social Study Subject
Based on Open Approach Innovation," Procedia — Social and Behavioral Sciences, 116, 1411-1415.

[2] Fuadi, I., Minarni, A. and Banjarnahor, H. 2017.-Analysis Of Students ‘ Self-regulated learning Ability In IX Grade At Junior High School ArRahman Percut," Novelty Juornals, Vol. 4, Issue. 2, pp. 153-159, March.

[3] Isoda. M, fnternational Comference on Mathematics Education research 2010 (ICMER 2010) Lesson Study: Problem Solving Approaches in Mathematics Education as a Japanese Experience,". Procedia Social an Behavioral Sciences. Vol.8. 2010. p. 17-27.2010.

[4] Minarni, A. 2017. Đeveloping Instruction Materials Based on Joyful PBL to Improve Students Mathematical Representation Ability". Journal See discussions, stats, and author profiles for this publicationat:https://www.researchgate.net/publication/311534697.

[5] OECD PISA.2012."Assessment and Analytical Framework: Mathematics, Reading,Science, Problem Solving and Financial Literacy". $\quad$ Available $\quad$ online from: http://www.masibas.my.id/2013/12/10-negara peringkatkemampuan.html

[6] Saragih. S., E. Napitupulu. E. E., \& Fauzi. A. 2017.Đeveloping Learning Model Based on Local Culture and Instrument for Mathematical Higher Order Thinking Ability". International Education Studies; Vol. 10, No. 6.ISSN 1913-9020 E-ISSN 1913-9039. Published by Canadian Center of Science and Education

[7] Napitupulu, E.E. 2008. Đeveloping Reasoning Skills and Problem Solving Through Problem Based Learning". Jurnal Pendidikan Matematika Paradikma UNIMED.

[8] Minarni, A. 2015.-Analysis of Self-regulated learning Ability of Public Junior High School Students". See discussions, stats, and author profiles for this publication at: https://www.researchgate.net/publication/311534697.

[9] Loong, T. E. (2013). International Students Self-Regulated Learning and its Relation to Mathematics Achievement in an Off Shore Australian Program. Academic Research International. Vol.4(5). September 2013.ISSN-L: 2223-9553. Sunway College, Malaysia

[10] Shunck, D.H. \& Zimmerman, B. J. (2011). Handbook of Self-Regulated of Learning and Performance. Routledge. New York and London.

[11] Tanriseven, I. (2014). A Tool That Can Be Effective in the SelfRegulated Learning of Pre-service Teachers: The Mind Map. Australian Journal of Teacher Education. Vol. 39(1). Januari 2014.p. 65-80

[12] Widjaja, W.B. \& Heck, A. 2003. How a Realistic Mathematics Education Approach and Micricomputer-Based Laboratory Worked in Lessons on Graphing at an Indonesian Junior High School”. Journal of Science and Mathematics Education in Southeast Asia. Vol. 26(2). P. 151. AMSTEL Institute, University of Amsterdam. Amsterdam, The Netherlands.

[13] Laurens, T., Adolfina, F., Rafafy, J. \& Leasa, M..2018. How Does Realistic Mathematics Education (RME) Improve Students“ Mathematics Cognitive Achievement?" EURASIA Journal of Mathematics, Science and Technology Education ISSN: 1305-8223 (online) 1305-8215 (print) 2018 14(2):569-578.

[14] Hiebert, J. \& Carpenter, T.P., Łearning and Teaching with Understanding. Dalam D.A. Grouws (Ed). Handbook of research on mathematics teaching and learning: A project of the National Council of Teachers of Mathematics". (pp. 65-97). New York, NY, England: Macmillan Publishing Co, Inc. 1992.

[15] Minarni, A. 2014. The Difference of Self-regulated learning Achievement of Public Junior High School Based on Learning Approach".

[16] Gravemeijer, K. 1994. Developing Realistic Mathematics Education. Utrecht: Freudenthal Institute.

[17] Shunck, D.H. \& Zimmerman, B. J. 2011. Handbook of Self-Regulated of Learning and Performance. Routledge. New York and London.

[18] Clements, D. H., \& Sarama, J. 2013. Rethinking early mathematics: What is research based curriculum for young children? In L. D. English \& J. T. Mulligan (Eds.), Reconceptualizing early mathematics learning (pp. 121-147).

[19] Loong, T. E. 2013. International Students Self-Regulated Learning and its Relation to Mathematics Achievement in an Off Shore Australian 
Program. Academic Research International. Vol.4(5). September 2013.ISSN-L: 2223-9553. Sunway College, Malaysia

[20] National Council of Teachers of Mathematics. 1991. Professional Standar for Teaching Mathematics. Reston, VA: NCTM

[21] Karnasih, I. 2008. Paper Presented in International Worksop : ICT for Teaching and Learning Mathematics, Unimed, Medan. (In Collaboration between UNIMED and QED Education Kuala Lumpur, Malaysia, 23-24 May 2008).

[22] NCTM. 1989. - Eurriculum and Evaluation Standars for School Mathematics". Reston, VA: NCTM.
[23] Lange, J. De. 1996. Using and Applying Mathematics in Education. in: A.J. Bishop, et

[24] Zulkardi. 2018. How to Design Mathematics Lessons based on the Realistic Approach?

[25] Treffers, A. 1991. Realistic mathematics education in The Netherlands 1980-1990. In

[26] Freudenthal, H. 1991. Revisiting Mathematics Education. China Lectures. Dordrecht: 